\title{
Effects of pneumothorax or pleural effusion on pulmonary function
}

\author{
JJ GILMARTIN, AJ WRIGHT, GJ GIBSON \\ From the Regional Cardiothoracic Centre, Freeman Hospital, Newcastle upon Tyne
}

ABSTRACT The effects of pneumothorax or pleural effusion on respiratory function as measured by the commonly applied tests were investigated by studying 13 patients (six with pneumothorax, seven with effusion) with and, as far as possible, without air or fluid in the pleural cavity. Measurements included spirometric volumes, carbon monoxide transfer factor (TLCO), and KCO by the single breath method, maximum expiratory flow-volume curves, and subdivisions of lung volume estimated by both inert gas dilution and body plethysmography. In patients with pneumothorax "pleural volume" was estimated as the difference between lung volumes measured by dilution and thoracic gas volume measured by plethysmography. In patients with effusion the change in "pleural volume" was equated with the volume of fluid subsequently aspirated. "Total thoracic capacity" (TTC) was estimated by adding total lung capacity (TLC) measured by dilution and "pleural volume." Both effusion and pneumothorax produced a restrictive ventilatory defect with reductions of vital capacity, functional residual capacity, and TLC. In the patients with effusion TTC fell after aspiration, suggesting that the pleural fluid produced relative expansion of the chest wall as well as compression of the lung. In patients with pneumothorax, however, there was no difference in TTC with and without air in the pleural space. In the presence of pleural air or fluid there was a slight decrease in TLCO and increase in KCO, with a small but significant increase in the rate of lung emptying during forced expiration.

The effects of pneumothorax and pleural effusion on pulmonary function as measured by the commonly applied tests are not well established. Most studies have concentrated on abnormalities of pulmonary gas exchange, and in particular there is little information on changes in carbon monoxide transfer factor, $\mathrm{KCO}$, or indices of airway function. The presence of air or fluid in the pleural space impairs full expansion of the ipsilateral lung but the effects on expansion of the contralateral lung are not clear. One point of practical importance is that the volume of a pneumothorax is likely to be included in any plethysmographic estimate of thoracic gas volume. Simple analysis of the static pressure-volume relationships in the affected hemithorax would suggest that uncoupling the lung from the chest wall would lead to some deflation of the lung and expansion of the chest wall to volumes determined by their

Address for correspondence: Dr JJ Gilmartin, Regional Cardiothoracic Centre, Freeman Hospital, Newcastle upon Tyne NE7 7DN. (Reprints will not be available.)

Accepted 15 October 1984 individual pressure-volume curves. ${ }^{1}$ With pneumothorax the effects should be more predictable as the pressure in the ipsilateral pleural space is uniform, provided that there is free communication around the lung. The effects of a pleural effusion on the lung and chest wall volumes are less certain as they are likely to be influenced by both the pleural liquid pressure (at the level of the effusion) and the pleural surface pressure (above the pleural effusion).

We have examined two groups of patients, one with pneumothorax and the other with pleural effusion, to study the effects of each on the results of the commonly applied tests of pulmonary function.

\section{Methods}

We studied six patients with pneumothorax (table 1 ). In three of these, measurements were made in the presence of a spontaneous pneumothorax and after complete resolution one to three weeks later. The other three patients with pneumothorax had small peripheral bronchial carcinomas and were 
Table 1 Details of patients and estimates of size of effusion or pneumothorax

\begin{tabular}{|c|c|c|c|c|c|c|c|}
\hline Group & $\begin{array}{l}\text { Patient } \\
\text { No }\end{array}$ & Sex & $\begin{array}{l}\text { Age } \\
(y)\end{array}$ & Diagnosis & Smoking & $\begin{array}{l}F E V_{1}^{*} \\
\text { (\% pred) }\end{array}$ & $\begin{array}{l}\Delta \text { (l) pleural volume" } \dagger \\
\end{array}$ \\
\hline \multirow[t]{3}{*}{ Pneumothorax } & $\begin{array}{l}1 \\
2 \\
3 \\
4\end{array}$ & $\begin{array}{l}\mathbf{F} \\
\mathbf{M} \\
\mathbf{M} \\
\mathbf{M}\end{array}$ & $\begin{array}{l}26 \\
19 \\
17 \\
53\end{array}$ & $\begin{array}{l}\text { Spontaneous } \\
\text { Spontaneous } \\
\text { Spontaneous } \\
\text { Iatrogenic } \\
\text { (carcinoma } \\
\text { bronchus) }\end{array}$ & $\begin{array}{l}+ \\
- \\
+\end{array}$ & $\begin{array}{r}110 \\
94 \\
92 \\
85\end{array}$ & $\begin{array}{l}0.4 \\
1 \cdot 5 \\
2 \cdot 05 \\
2 \cdot 0\end{array}$ \\
\hline & 5 & $\mathbf{M}$ & 66 & $\begin{array}{l}\text { Iatrogenic } \\
\text { (carcinoma } \\
\text { bronchus) }\end{array}$ & + & 55 & $4 \cdot 2$ \\
\hline & 6 & $\mathbf{M}$ & 64 & $\begin{array}{l}\text { Iatrogenic } \\
\text { (carcinoma } \\
\text { bronchus) }\end{array}$ & + & 75 & $2 \cdot 15$ \\
\hline \multirow[t]{4}{*}{ Pleural effusion } & $\begin{array}{l}7 \\
8\end{array}$ & $\begin{array}{l}\mathbf{M} \\
\mathbf{M}\end{array}$ & $\begin{array}{l}62 \\
61\end{array}$ & $\begin{array}{l}\text { Mesothelioma } \\
\text { Carcinoma } \\
\text { bronchus }\end{array}$ & $\overline{+}$ & $\begin{array}{l}54 \\
36\end{array}$ & $\begin{array}{l}1 \cdot 1 \\
1 \cdot 3\end{array}$ \\
\hline & 9 & $\mathbf{M}$ & 69 & $\begin{array}{c}\text { Carcinoma } \\
\text { bronchus }\end{array}$ & + & 51 & $1 \cdot 1$ \\
\hline & $\begin{array}{l}10 \\
11 \\
12\end{array}$ & $\begin{array}{l}\mathbf{M} \\
\mathbf{M} \\
\mathbf{M}\end{array}$ & $\begin{array}{l}75 \\
60 \\
62\end{array}$ & $\begin{array}{l}\text { Empyema } \\
\text { Mesothelioma } \\
\text { Carcinoma } \\
\text { bronchus }\end{array}$ & $\begin{array}{l}+ \\
\text { ex } \\
+\end{array}$ & $\begin{array}{l}68 \\
56 \\
55\end{array}$ & $\begin{array}{l}2 \cdot 5 \\
2 \cdot 5 \\
0 \cdot 8\end{array}$ \\
\hline & $13 \ddagger$ & $\mathbf{M}$ & 67 & Tuberculosis & - & 92 & 0.8 \\
\hline
\end{tabular}

*After re-expansion (patients 1-3), before development of pneumothorax (patients 4-6), or after aspiration of effusion (patients 7-13). †Volume of fluid aspirated or estimated volume of pneumothorax (see text).

$\ddagger$ Lung volume estimated by plethysmography only.

being investigated by percutaneous needle biopsy. Pulmonary function tests were performed before needle biopsy in several such patients and in the three reported here a pneumothorax developed as a complication of the biopsy.

Studies were performed in seven patients before and within 24 hours of aspiration of $0 \cdot 8-2 \cdot 5$ litres of pleural fluid. The diagnoses in these patients were mesothelioma (2), bronchial carcinoma (3), empyema, and tuberculous effusion (table 1). In the patients with mesothelioma the diagnosis did not come to light until later.

Two of the patients with pneumothorax and two of the patients with pleural effusion were studied on more than one occasion after recurrences.

One second forced expiratory volume $\left(\mathrm{FEV}_{1}\right)$ and vital capacity (VC) were recorded with a bellows spirometer; functional residual capacity (FRC), total lung capacity (TLC), and residual volume (RV) were recorded by helium dilution, and thoracic gas volume was also measured by plethysmography, a constant volume plethysmograph ${ }^{2}$ being used. Measurements of lung volumes with and without a pneumothorax or before and after pleural aspiration were available for all 13 patients and on a total of 19 occasions. Transfer factor (TLCO $=$ carbon monoxide diffusing capacity $=D_{L} C O$ ) was measured in triplicate by the single breath method of Ogilvie $\mathrm{et} \mathrm{al}^{3}$ on the basis of the single breath estimate of alveolar volume (VA). ${ }^{4}$ The transfer coefficient KCO, was calculated as TLCO/VA. Satisfactory sequential measurements of transfer factor were obtained in 12 patients. In none of the patients after aspiration was a radiologically visible pneumothorax present, but in all the patients with pleural effusion residual fluid or pleural thickening was detectable as blunting of the costophrenic angle on the postaspiration radiograph.

Measurements of lung volumes and transfer factor were expressed as percentages of predicted values on the basis of standard regression equations. ${ }^{5}$

Maximum expiratory flow-volume curves (MEFV) were obtained with a rolling seal spirometer (Ohio 842) and either a storage oscilloscope or a rapid X-Y plotter. At least three closely reproducible curves were obtained with and without a pneumothorax in two patients and before and after pleural aspiration in six patients. From the MEFV curves we obtained the flow at $50 \%$ VC ( VEmax $\left._{50}\right)$. The mean slope of the curve between $50 \%$ and $75 \%$ VC was also calculated and the time constant of lung emptying during forced expiration was computed by taking the reciprocal of this slope ${ }^{\circ}\left(\mathrm{V} / \dot{\mathrm{V}}_{50-75}\right)$. These indices we obtained on each occasion from the MEFV curve in which the VC was greatest.

In the patients with effusions the change in pleural volume ( $\Delta$ "pleural volume") after aspiration was assumed to be equal to the volume of fluid removed and the values are given in table 1 . No similar direct measurements of the volume of pneumothorax were available and we have therefore estimated this from the change in the difference between thoracic gas volume measured plethysmographically at end expiration and functional residual capacity (FRC) esti- 
mated by helium dilution. This assumes that the pneumothorax undergoes similar pressure changes to alveolar gas during the panting manoeuvre and
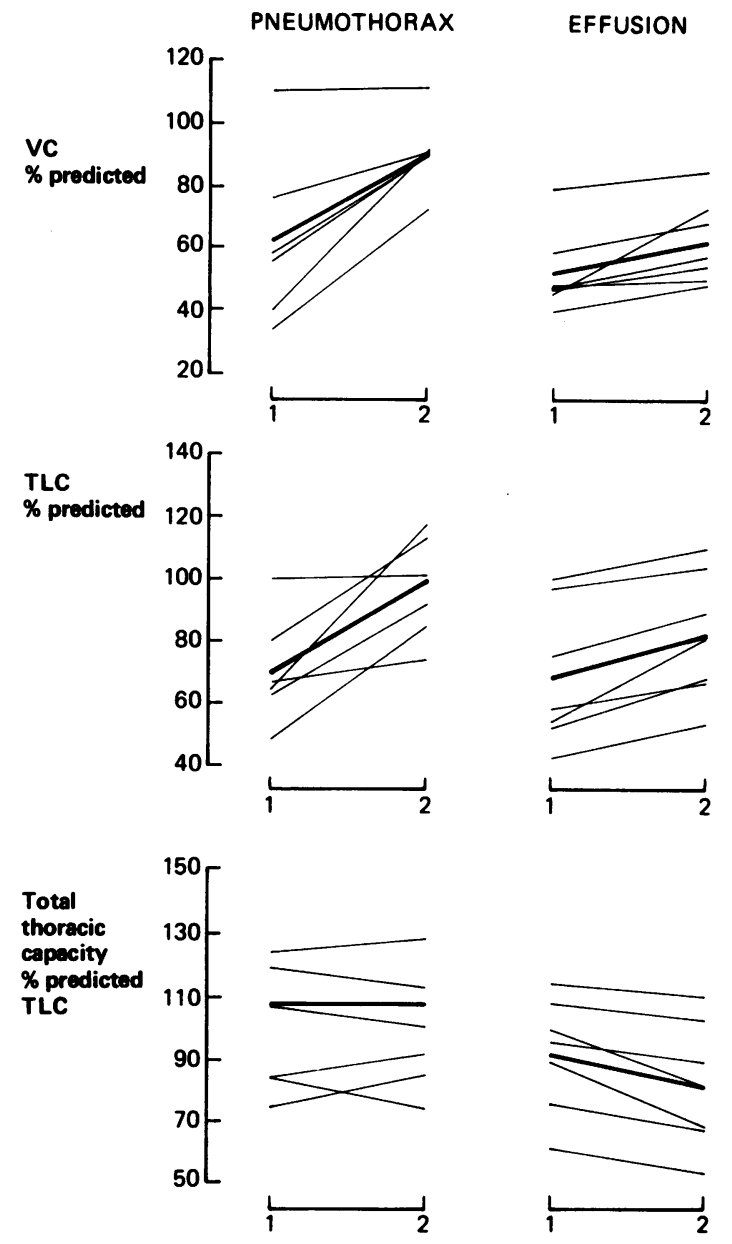

Fig 1 The upper four panels show individual values of vital capacity (VC) and total lung capacity (TLC) (helium dilution) expressed as percentages of predicted values in patients with a pneumothorax (left) or effusion (right). 1 and 2 represent respectively measurements with and without air or fuid in the pleural space and heavy lines represent mean values. The two lower panels show the effect of effusion and pneumothorax on total thoracic capacity (see text) expressed as a percentage of predicted TLC. The changes in VC $(p<0.02)$ and TLC $(p<0.05)$ for both conditions were significant. There was no mean difference in total thoracic capacity in patients with a pneumothorax, but a significant fall $(p<0.01)$ occurred after aspiration in patients with effusion. that any effect of maldistribution of gas tending to underestimate the true lung volume was the same on the two occasions. The values of $\Delta$ "pleural volume" thus estimated are given in table 1 . Total thoracic capacity at full inflation (TTC) was estimated by adding TLC (measured by helium dilution) to the "pleural volume" - that is, the volume of pleural fluid subsequently aspirated or the estimated size of pneumothorax.

Differences in individual indices with and without air or fluid were sought by paired $t$ tests. The relationships between changes in physiological variables and $\Delta$ "pleural volume" were examined by using the linear correlation coefficient.

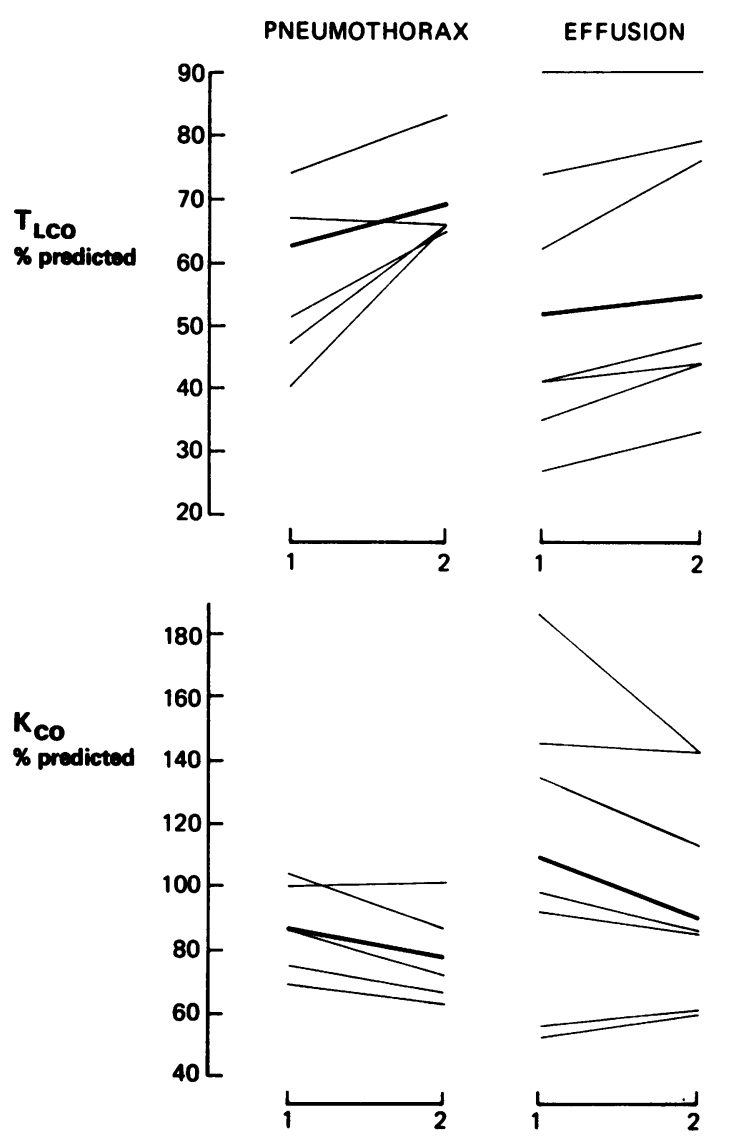

Fig 2 Effect of air or fuid on transfer factor (TLCO) and $K C O$ in 12 patients (expressed as percentages of predicted values). (Conventions as in figure 1.) There was a tendency for TLCO to fall and KCO to increase with air or fuid in the pleural cavity. The differences were not significant for the pneumothorax and effusion groups separately but when the two groups were pooled there was a significant difference $(p<0.005$ for $T L C O,<0.05$ for $\mathrm{KCO})$. 
Results

Individual values of lung volumes measured by helium dilution, estimated total thoracic capacity, TLCO, and KCO are shown in figures 1 and 2. Since the effects of pneumothorax and pleural effusion on these indices were broadly similar the results have been combined and are summarised in table 2 . For patients studied on more than one occasion the information displayed in figures 1 and 2 and in tables 1 and 2 refers to the occasions when the pneumothorax or effusion was largest. In brief, the effects of pneumothorax or effusion on the results of the conventional tests were a reduction in $\mathrm{FEV}_{1}, \mathrm{VC}$ FRC, RV, and TLC; a small reduction in TLCO; and a small increase in $\mathrm{KCO}$. The estimated changes in total thoracic capacity showed some differences between effusions and pneumothorax. With aspiration of an effusion the fall in TTC mirrored the increase in TLC and in VC. With resolution of the pneumothoraces, however, the anticipated fall in TTC did not occur and in three of the patients there was an increase in TTC after resolution.

We have examined the relationships between $\Delta$ "pleural volume" in an individual and the changes in the various subdivisions of lung volume (measured by helium dilution-fig 3). In this figure the information obtained on all occasions is included-that is, the results are based on 19 pairs of estimations. As expected, there were significant relationships between the size of the pneumothorax or effusion and the changes in vital capacity or TLC (fig 3); but the $\Delta$ "pleural volume" usually exceeded the change in vital capacity or TLC.

The maximum flow-volume curve showed that maximum expiratory flow at mid vital capacity was slightly less, but the time constant of lung emptying was significantly shorter in the presence of a pneumothorax or effusion (table 2).

\section{Discussion}

The functional abnormalities found in patients with pneumothorax or effusion are often not simply due to the presence of pleural air or fluid alone as many such patients will have underlying lung disease. Even in young people with spontaneous pneumothorax and apparently otherwise healthy lungs evidence of subclinical emphysema is frequently found,' and in two of our three patients with spontaneous pneumothorax the TLCO and KCO were still reduced after resolution. The other three

Table 2 Effects of pneumothorax or effusion on lung volumes, transfer factor, and maximum flow-volume curves

\begin{tabular}{|c|c|c|c|c|}
\hline & $\begin{array}{l}\text { No of } \\
\text { patients }\end{array}$ & $\underset{\text { range }}{\text { Mean }}(S D) 1, *$ & $\begin{array}{l}\text { Mean }(S D) 2, * \\
\text { range }\end{array}$ & $\begin{array}{l}p \text { for } \\
\text { difference }\end{array}$ \\
\hline FEV $1 \%$ predicted $)$ & 13 & $\begin{array}{l}53 \cdot 2(23 \cdot 7) \\
21-104\end{array}$ & $\begin{array}{l}71 \cdot 0(21 \cdot 9) \\
36-110\end{array}$ & $<0.001$ \\
\hline VC (\% predicted) & 13 & $\begin{array}{l}56 \cdot 5(21 \cdot 0) \\
33-110\end{array}$ & $\begin{array}{l}75 \cdot 6(19 \cdot 7) \\
48-111\end{array}$ & $<0.005$ \\
\hline FRC ( $\%$ predicted $) \dagger$ & 13 & $\begin{array}{l}70 \cdot 2(26 \cdot 3) \\
38-139\end{array}$ & $\begin{array}{l}97 \cdot 6(34 \cdot 0) \\
50-155\end{array}$ & $<0.001$ \\
\hline TLC (\% predicted) $\dagger$ & 13 & $\begin{array}{l}69 \cdot 1(19 \cdot 9) \\
42-100\end{array}$ & $\begin{array}{l}89 \cdot 5(21 \cdot 2) \\
67-128\end{array}$ & $<0.001$ \\
\hline TTC (\% predicted TLC) & 13 & $\begin{array}{l}94 \cdot 9(18 \cdot 3) \\
61-124\end{array}$ & $\begin{array}{l}89.0(20.5) \\
53-128\end{array}$ & NS \\
\hline RV (\% predicted) $\dagger$ & 13 & $\begin{array}{l}83 \cdot 5(29 \cdot 3) \\
35-135\end{array}$ & $\begin{array}{l}119 \cdot 3(57 \cdot 5) \\
35-230\end{array}$ & NS \\
\hline TLCO (\% predicted) & 12 & $\begin{array}{l}54 \cdot 1(19 \cdot 1) \\
27-74\end{array}$ & $\begin{array}{l}63 \cdot 3(17 \cdot 7) \\
33-90\end{array}$ & $<0.005$ \\
\hline KCO (\% predicted) & 12 & $\begin{array}{l}99 \cdot 9(38 \cdot 9) \\
52-186\end{array}$ & $\begin{array}{l}89.9(29.8) \\
59-143\end{array}$ & $<0.05$ \\
\hline$\dot{V} \max _{s 0}\left(1 s^{-1}\right)$ & 8 & $\begin{array}{l}2 \cdot 44(1 \cdot 66) \\
0.3-4 \cdot 6\end{array}$ & $\underset{0.5-4.8}{2.67(1.48)}$ & $<0.05$ \\
\hline $\begin{array}{l}\text { Time constant of lung emptying } \\
\text { during forced expiration } \\
\left(\mathrm{V} / \mathrm{V}_{50-75} \mathrm{~s}\right)\end{array}$ & 8 & $\begin{array}{l}0.482(0.35) \\
0.27-1.3\end{array}$ & $\begin{array}{c}0.64(0.39) \\
0.42-1.59\end{array}$ & $<0.01$ \\
\hline
\end{tabular}

* 1 -in presence of effusion or pneumothorax; 2-after re-expansion (patients 1-3) or before development of pneumothorax (patients 4-6), or after aspiration of effusion (patients 7-13).

†By helium dilution.

VC-Vital capacity; FRC - functional residual capacity; TLC - total lung capacity; TTC - total thoracic capacity; RV-residual volume;

TLCO-transfer factor; $\mathrm{KCO}-$ transfer coefficient; $\mathrm{VEmax}_{\text {so }} 1 \mathrm{~s}^{-1}$-maximum expiratory flow at $50 \%$ VC expired; NS—not significant. 
patients with pneumothorax all had bronchial carcinoma and some degree of airflow obstruction. Study of the "pure" effects of pleural effusion is even more difficult. Patients frequently have pain before or after aspiration but in none of our patients did pain appear to limit the performance of the tests. It is, however, likely that in none of the patients described here were the functional abnormalities due solely to the presence of pleural fluid as many had chronic airways obstruction and in all patients a small amount of pleural fluid was probably still present after aspiration. Nevertheless, since we have studied the patients with and, so far as possible, without pleural fluid or air, the within subject changes observed in the results of routine lung function tests should be valid guides to the effects of the volume of pleural fluid subsequently aspirated or air resorbed in these patients.

We have used a plethysmographic estimate of pneumothorax size for relating the magnitude of changes in lung function to the size of the pneumothorax and for estimating "pleural volume." This assumes that air in the pleural cavity is subject to the same degree of compression and rarefaction as alveolar gas and that any maldistribution of gas was the same with and without a pneumothorax. Neither of these assumptions may be completely valid. In theory, the body plethysmograph may underestimate the volume of compartments, such as a pneumothorax, with a low surface to volume ratio since gas compression and rarefaction are likely to be less perfectly isothermal than within alveoli,

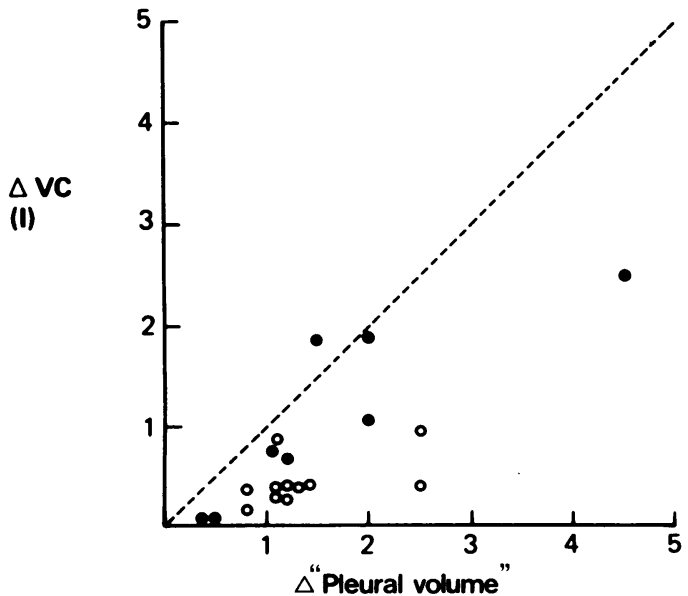

(a) whose high surface to volume ratio allows heat exchange with the walls of the gas containing units, thus helping to maintain isothermal conditions. ${ }^{8} \mathrm{We}$ know of no direct evidence on the accuracy of thoracic gas volume estimation in the presence of a pneumothorax. This phenomenon may account for the surprising finding that total thoracic capacity was less than predicted TLC in some patients in the presence of a pneumothorax (fig 1); but it was also noteworthy that the two patients with the lowest estimated TTC had pronounced mediastinal shift visible radiographically, and this may have restricted expansion of the unaffected lung. Early measurements during artificial induction of a pneumothorax for tuberculosis ${ }^{y}$ and more recent radioisotope studies $^{10}$ support the conclusion that a pneumothorax significantly. impedes expansion of the contralateral lung.

Published data on the effects of pneumothorax and pleural effusion are few, ${ }^{11-15}$ but it appears that, despite the theoretical differences between the presence of air and fluid in the pleural space, their functional consequences are similar. The finding that reductions in lung volumes are, in general, smaller than the size of the effusion or pneumothorax broadly agrees with previous observations ${ }^{11-15}$ and we have in addition shown significant relationships between the estimated size of the effusion or pneumothorax and the reduction in VC or TLC (fig 3). The implication is that with either effusion or pneumothorax expansion of the pleural space is accommodated partly by deflation of the lung and

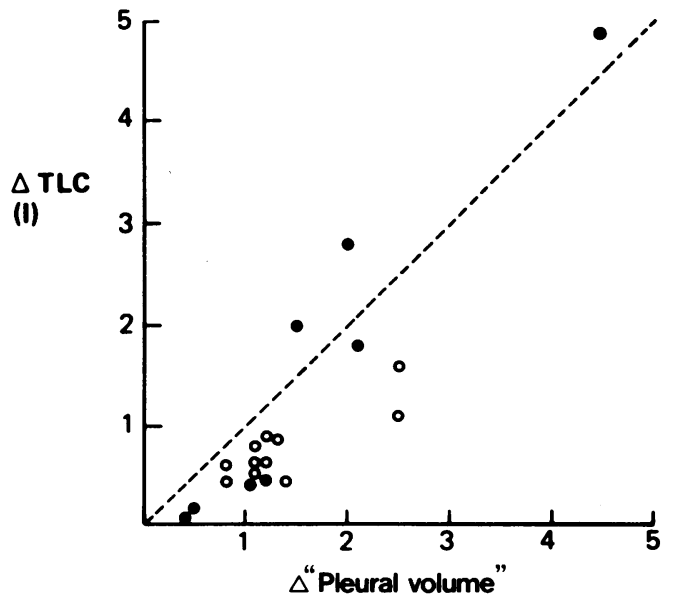

(b)

Fig 3 (a) Change in vital capacity $(\Delta V C)$ and (b) change in total lung capacity ( $\Delta T L C)$ measured by helium dilution plotted against estimated change in "pleural volume" (see text). Solid circles represent patients with pneumothorax (6 patients studied on 8 occasions); open circles those with effusion (7 patients studied on 11 occasions). The broken line is the line of identity. There were significant correlations between $\Delta$ "pleural volume" and VC $(r=0.765)$ and TLC $(r=0.898)$ but $\triangle V C$ and $\triangle T L C$ were usually less than the estimated $\Delta$ "pleural volume". 
partly by relative expansion of the ipsilateral chest wall. This was pointed out in early studies of pneumothorax ${ }^{11}$ is and more recently by Estenne and colleagues ${ }^{14}$ in pleural effusion. Despite this distortion of the chest wall, the results in our patient suggest that in both pleural effusion and pneumothorax the total thoracic capacity at full inflation is unlikely to be greater than normal and is frequently less than normal.

The information from the flow-volume curves suggests that the lungs empty slightly faster during forced expiration in the presence of pleural air or fluid. At first sight this may be surprising, but it could result from a reduction in lung volume disproportionate to any effect on airway function. Similar arguments have been advanced in relation to the maximum flow-volume curves in patients with lung shrinkage from pulmonary fibrosis, ${ }^{16}$ and the effects are similar to those of strapping the chest wall of normal subjects. ${ }^{17}$ In simple terms, if pleural fluid or air effectively reduces the number of functioning compliant lung units, airway size will remain appropriate for the lung recoil pressure but will be inappropriately large for the lung volume, so that volume corrected indices such as the slope of the flow-volume curve appear supranormal. If airway function were totally unaffected then maximum flow at $50 \%$ of measured VC should in absolute terms remain unchanged. The slight reduction in VEmax found in our subjects is still compatible with this hypothesis, as any airways subtending nonfunctional lung units can themselves no longer contribute to airflow. In terms of the equal pressure point analysis, the time constant of lung emptying is equal to the product of upstream resistance and lung compliance, so that if upstream resistance remains constant and lung compliance falls (perhaps because of microatelectasis) the time constant of lung emptying shortens. Estenne et al $^{14}$ have shown an increase in static lung compliance after pleural aspiration, which would be consistent with this hypothesis.

In conclusion, pleural effusion and pneumothorax have similar effects on the mechanical function of the lungs and on transfer factor. In addition to impairing full expansion of the ipsilateral lung, there may be an effect on the contralateral lung and there is usually relative distension of the ipsilateral chest wall. As with other extrapulmonary causes of restriction of lung volumes, there is an accompanying small reduction in transfer factor and an increase in $\mathrm{KCO}$. The reduction in lung volumes is disproportionate to the minor effects on airway function, so that the lungs empty more quickly; in this respect the effects are similar to those found in patients with intrapulmonary volume restriction such as pulmonary fibrosis.
We are grateful to Dr S Nariman for allowing us to study patients under his care, to $\mathrm{Mr} \mathrm{T}$ Stone for technical help, and to Mrs B Wears for typing the manuscript.

\section{References}

1 Fenn WO. The pressure volume diagram of the breathing mechanism. In: Boothby WM, ed. Respiratory physiology in aviation. Randolph Field, Texas: United States Air Force School of Aviation Medicine, 1954:19-27.

2 DuBois AB, Botelho SY, Bedell GN, et al. A rapid plethysmographic method for measuring thoracic gas volume. J Clin Invest 1956;35:322-6.

3 Ogilvie CM, Forster RE, Blakemore WS, Morton JW. A standardized breath holding technique for the clinical measurement of the diffusing capacity of the lung for carbon monoxide. J Clin Invest 1957;36:1-17.

4 McGrath MW, Thomson ML. The effect of age, body size and lung volume change on alveolar-capillary permeability and diffusing capacity in man. $J$ Physiol 1959; 146: 572-82.

5 Cotes JE. Lung function: principles and application in medicine. 4th ed. Oxford: Blackwell Scientific Publications, 1979:329-87.

6 Lapp NL, Hyatt RE. Some factors affecting the relationship of maximal expiratory flow to lung volume in health and disease. Dis Chest 1967;51:475-81.

7 De Troyer A, Yernault J-C, Rodenstein D, et al. Pulmonary function in patients with primary spontaneous pneumothorax. Bull Europ Physiopathol Respir 1978; 14:31-9.

8 Briscoe WA. Lung volumes. In: Fenn WO, Rahn H, eds. Handbook of physiology. Section 3: Respiration. Vol II. Washington DC: American Physiological Society, 1964:1345-79.

9 Bence AE, Lanari A, Rodrigues BJ. Relacion entre el volumen del aire insuflado en la camara pleural y la disminucion del volumen pulmonar. Estudio bronchoespirometrico. Medicina 1948;8:16-21.

10 Anthonisen NR. Regional lung function in spontaneous pneumothorax. Am Rev Respir Dis 1977; 115:873-6.

.11 Christie RV, McIntosh CA. The lung volume and respiratory exchange after pneumothorax. $Q \mathrm{~J} \mathrm{Med}$ 1936;5:445-54.

12 Yoo OH, Ting EY. The effects of pleural effusion on pulmonary function. Am Rev Respir Dis 1964;89:5563.

13 Brown NE, Zamel N, Aberman A. Changes in pulmonary mechanics and gas exchange following thoracentesis. Chest 1978;74:540-2.

14 Estenne M, Yernault J-C, De Troyer A. The mechanism of relief of dyspnoea after thoracentesis in patients with large pleural effusion. Am J Med 1983;74:813-9.

15 Heaf PJD, Prime FJ. Mechanical aspects of artificial pneumothorax. Lancet 1954;ii:468-70.

16 Gibson GJ, Pride NB. Pulmonary mechanics in fibrosing alveolitis: the effects of lung shrinkage. Am Rev Respir Dis 1977;116:637-47.

17 Stubbs SE, Hyatt RE. Effect of increased lung recoil pressure on maximal expiratory flow in normal subjects. J Appl Physiol 1972;32:325-31. 